\title{
Discontinuously Stiffened Composite Panel under Compressive Loading
}

\author{
LEVon Minnetyan* and James M. Rivers** \\ Clarkson University \\ Potsdam, New York 13699-5710 \\ Christos C. Chamis $†$ and Pappu L. N. Murthy $\ddagger$ \\ National Aeronautics and Space Administration \\ Lewis Research Center \\ Cleveland, $\mathrm{OH} 44135$
}

\begin{abstract}
The design of composite structures requires an evaluation of their safety and durability under service loads and possible overload conditions. This paper presents a computational tool that has been developed to examine the response of stiffened composite panels via the simulation of damage initiation, growth, accumulation, progression, and propagation to structural fracture or collapse. The structural durability of a composite panel with a discontinuous stiffener is investigated under compressive loading induced by the gradual displacement of an end support. Results indicate damage initiation and progression to have significant effects on structural behavior under loading. Utilization of an integrated computer code for structural durability assessment is demonstrated.
\end{abstract}

KEY WORDS : composite materials, composites, computational simulation, damage, degradation, durability, fracture, laminates, simulation, stiffened panel, structural degradation.

\section{INTRODUCTION}

STIFFENED COMPOSITE PANELS are used in many structural components to satisfy requirements of reduced weight, increased stiffness, and stability. Design considerations with regard to the durability of stiffened panels require an a priori evaluation of damage initiation and propagation mechanisms under expected

\footnotetext{
* Associate Professor, Department of Civil and Environmental Engineering. Author to whom currespondence should be addressed.

** Graduate Student, Department of Civil and Environmental Engineering.

$\dagger$ Senior Aerospace Scientist, Structures Division.

$¥$ Senior Acrospace Engineer, Structures Division.
} 
service loading. Concerns for safety and survivability of critical components require a quantification of the composite structural damage tolerance during overloads.

The numerous options available in the tailoring of composite structures make composites more versatile for fulfilling structural design requirements. However, these same design flexibilities render the assessment of composite structural response and durability more complex, prolonging the design and certification process and adding to the cost of the final product. It is difficult to evaluate composite structures because of the complexities in predicting their overall congruity and performance, especially when structural degradation and damage propagation take place. The predictions of damage initiation, damage growth, and propagation to fracture are important in evaluating the load carrying capacity, damage tolerance, safety, and reliability of composite structures. Quantification of the structural fracture resistance is also fundamental for evaluating the durability/life of composite structures. The most effective way to obtain this quantification is through integrated computer codes that couple composite mechanics with structural analysis and damage progression modelling. The COmposite Durability STRuctural ANalysis (CODSTRAN) computer code [1] has been developed for this purpose. The simulation of progressive fracture by CODSTRAN has been validated to be in reasonable agreement with experimental data from tensile tests [2]. Recent additions to CODSTRAN have enabled investigation of the effects of composite degradation on structural response [3], composite damage induced by dynamic loading [4], composite structures global fracture toughness [5], effect of the hygrothermal environment on durability [6], structural damage and fracture in composite thin shells [7], structural durability of a composite pressure vessel [8], overall evaluation of damage progression in composites [9], damage and fracture of stiffened shell panels [10], and design implications of progressive fracture in composite shell structures [11]. The present paper demonstrates the capability of CODSTRAN to evaluate the response and degradation of a discontinuously stiffened composite panel under a displacement controlled loading.

\section{THE CODSTRAN METHODOLOGY}

CODSTRAN is an open-ended computer code integrating selected modules on composite mechanics, damage progression modelling, and finite element analysis. The damage progression module [1] keeps a detailed account of composite degradation for the entire structure and also acts as the master executive module that directs the composite mechanics module [12] to perform micromechanics, macromechanics. laminate analysis and synthesis functions. It also calls the finite element analysis module [13] with anisotropic thick shell analysis capability to model laminated composites for global structural response. A convenient feature of the utilized finite element module is that structural properties are input and generalized stress resultants are output at the nodes rather than for the elements. The anisotropic generalized stress-strain relationships for each node are revised according to the composite damage evaluated after each finite element analysis. Subsequent to damage and composite degradation, the model is automatically 


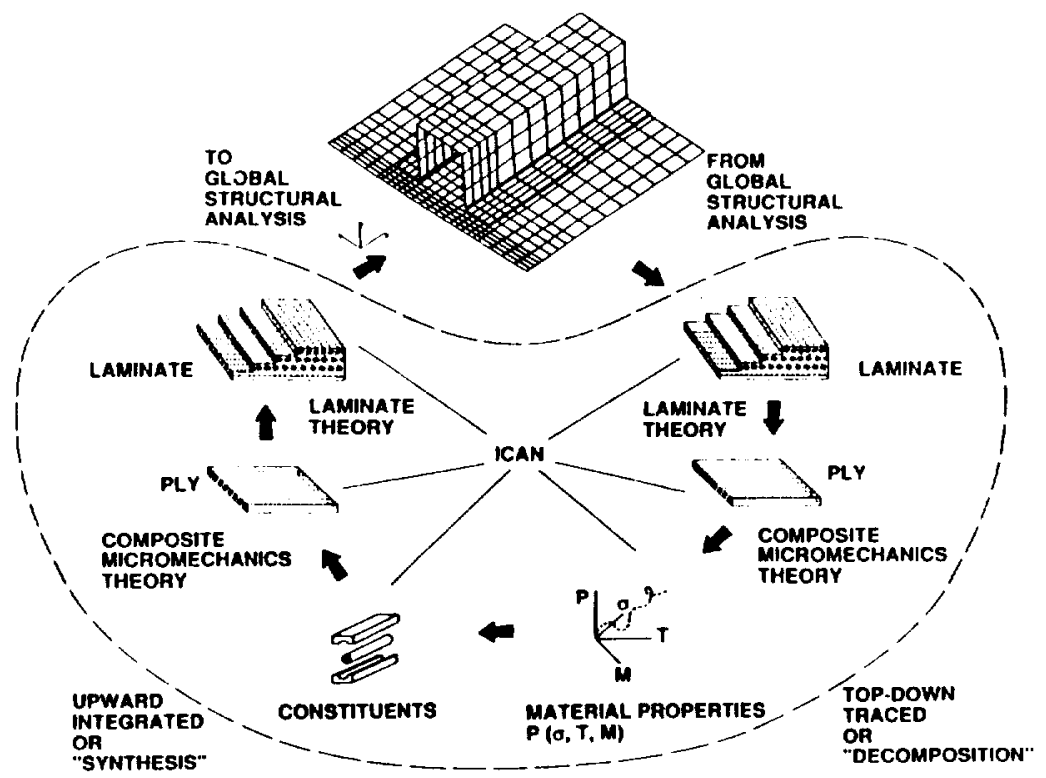

Figure 1. CODSTRAN simulation cycle.

updated with a new finite element mesh and properties before the structure is reanalyzed for further deformation and damage.

Figure 1 shows a schematic of the computational simulation cycle in CODSTRAN. The ICAN composite mechanics module is called before and after each finite element analysis. Prior to each finite element analysis, the ICAN module computes the composite properties from the fiber and matrix constituent characteristics and the composite layup. The laminate properties may be different at each node. The finite element analysis module accepts the composite properties that are computed by the ICAN module and performs the analysis at each load increment. After an incremental finite element analysis, the computed generalized nodal force resultants and deformations are supplied to the ICAN module that evaluates the nature and amount of local damage, if any, in the plies of the composite laminate. Individual ply failure modes monitored by CODSTRAN include the failure criteria associated with the negative and positive limits of the six ply-stress components $\left(\sigma_{111}, \sigma_{122}, \sigma_{133}, \sigma_{112}, \sigma_{123}, \sigma_{113}\right)$ and a combined stress or modified distortion energy (MDE) failure criterion, and interply delamination due to relative rotation (RR) of the plies [12].

For the purpose of the present discussion, the following terminology is used to describe the various stages of degradation in the composite structure: (1) damage initiation refers to the start of damage induced by loading that the composite structure is designed to carry; (2) damage growth is the progression of damage from the location of damage initiation to adjacent regions; (3) damage accumula- 
tion is the increase in the amount of damage in the damaged region with additional damage modes becoming active; (4) nodal fracture is a through-thethickness fracture at a node because of major tensile or compressive failures in all plies of the laminate. Nodal fracture is usually a characteristic in precipitating rapid damage propagation toward structural fracture.

\section{STIFFENED COMPOSITE PANEL}

The demonstration example for this paper consists of a stiffened composite panel, depicted in Figures $2 a$ and $2 b$, subjected to axial compression. The finite element model shown in Figure 2 a uses thick shell elements with duplicate nodes where there are sudden changes in composite properties. The use of duplicate nodes to achieve accurate structural representation at locations of abrupt change in the laminate was discussed in a previous paper [10]. The composite system for this example is made of AS-4 graphite fibers in a high-modulus, high-strength epoxy matrix (AS-4/HMHS). The corresponding fiber and matrix properties are obtained from a databank of composite constituent material properties resident in CODSTRAN [12].

The properties used for the AS-4 graphite fibers and HMHS epoxy matrix are given as follows:

\section{AS-4 Fiber Properties:}

Number of fibers per end $=10000$

Fiber diameter $=0.00762 \mathrm{~mm}(0.300 \mathrm{E}-3 \mathrm{in})$

Fiber Density $\left.=4.04 \mathrm{E}-7 \mathrm{Kg} / \mathrm{m}^{3}\right)\left(0.063 \mathrm{lb} / \mathrm{in}^{3}\right)$

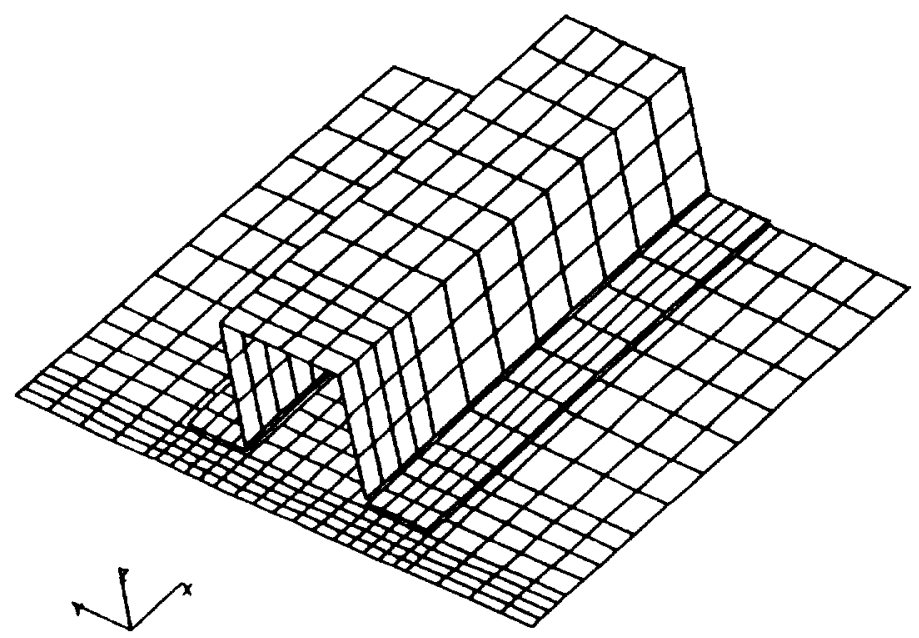

Figure 2a. Stiffened composite panel finite element model AS-4/HMHS $\left[[0 / \pm 45 / 90]_{s}\right]_{6}$. 

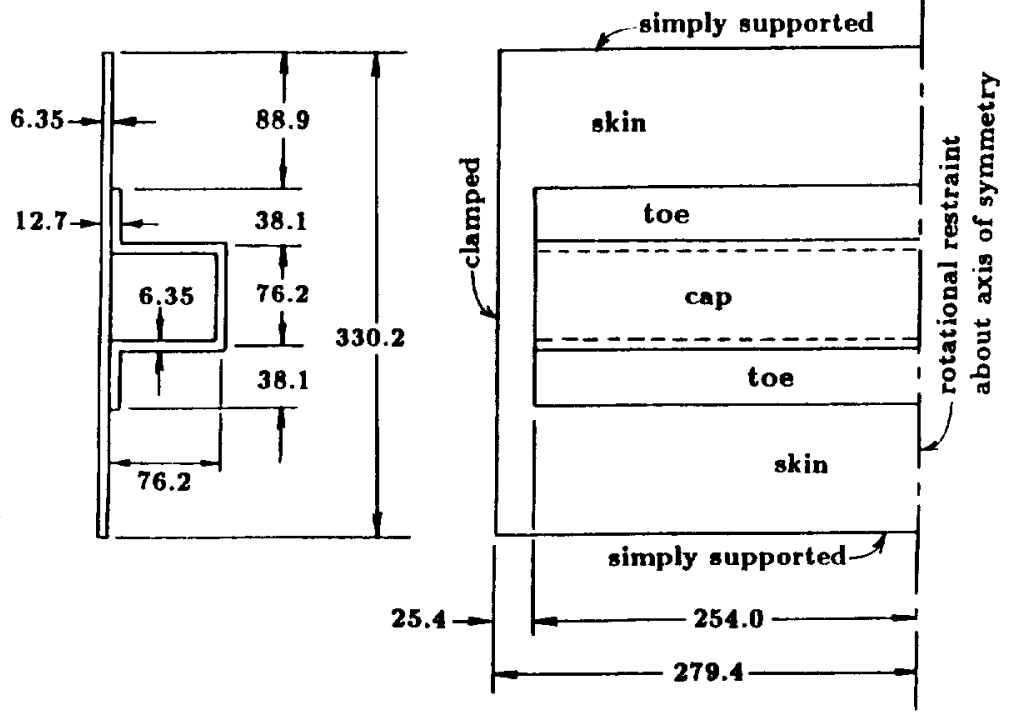

Figure 2b. Stiffened composite penel AS-4/HMHS $\left[[0 / \pm 45 / 90]_{s}\right]_{6}$ cross section and plan (all dimensions are in $\mathrm{mm}$ ).

Longitudinal normal modulus $=227 \mathrm{GPa}(32.90 \mathrm{E}+6 \mathrm{psi})$

Transverse normal modulus $=13.7 \mathrm{GPa}(1.99 \mathrm{E}+6 \mathrm{psi})$

Poisson's ratio $\left(\nu_{12}\right)=0.20$

Poisson's ratio $\left(\nu_{23}\right)=0.25$

Shear modulus $\left(G_{12}\right)=13.8 \mathrm{GPa}(2.00 \mathrm{E}+6 \mathrm{psi})$

Shear modulus $\left(G_{23}\right)=6.90 \mathrm{GPa}(1.00 \mathrm{E}+6 \mathrm{psi})$

Longitudinal thermal expansion coefficient $=-1.0 \mathrm{E}-6 /{ }^{\circ} \mathrm{C}\left(-0.55 \mathrm{E}-6 /{ }^{\circ} \mathrm{F}\right)$

Transverse thermal expansion coefficient $=1.0 \mathrm{E}-5 /{ }^{\circ} \mathrm{C}\left(+0.55 \mathrm{E}-5 /{ }^{\circ} \mathrm{F}\right)$

Longitudinal heat conductivity $=43.4 \mathrm{~J}-\mathrm{m} / \mathrm{hr} / \mathrm{m}^{2} /{ }^{\circ} \mathrm{C}(580 \mathrm{BTU}-$ in $/ \mathrm{hr} / \mathrm{in}^{2} /^{\circ} \mathrm{F}$ )

Transverse heat conductivity $=4.34 \mathrm{~J}-\mathrm{m} / \mathrm{hr} / \mathrm{m}^{2} /{ }^{\circ} \mathrm{C}(58 \mathrm{BTU}-$ in $/ \mathrm{hr} / \mathrm{in}^{2} /{ }^{\circ} \mathrm{F}$ )

Heat capacity $=712 \mathrm{~J} / \mathrm{Kg} /{ }^{\circ} \mathrm{C}\left(0.17 \mathrm{BTU} / \mathrm{lb} /{ }^{\circ} \mathrm{F}\right)$

Tensile strength $=3,723 \mathrm{MPa}(540 \mathrm{ksi})$

Compressive strength $=3,351 \mathrm{MPa}(486 \mathrm{ksi})$

\section{HMHS Matrix Properties:}

Matrix density $=3.40 \mathrm{E}-7 \mathrm{Kg} / \mathrm{m}^{3}\left(0.0457 \mathrm{lb} / \mathrm{in}^{3}\right)$

Normal modulus $=4.27 \mathrm{GPa}(620 \mathrm{ksi})$ 
Poisson's ratio $=0.34$

Coefficient of thermal expansion $=0.72 /{ }^{\circ} \mathrm{C}\left(0.4 \mathrm{E}-4 /{ }^{\circ} \mathrm{F}\right)$

Heat conductivity $=1.25 \mathrm{BTU}-\mathrm{in} / \mathrm{hr} / \mathrm{in}^{2} /{ }^{\circ} \mathrm{F}$

Heat capacity $=0.25 \mathrm{BTU} / \mathrm{lb} /{ }^{\circ} \mathrm{F}$

Tensile strength $=84.8 \mathrm{MPa}(12.3 \mathrm{ksi})$

Compressive strength $=423 \mathrm{MPa}(61.3 \mathrm{ksi})$

Shear strength $=148 \mathrm{MPa}(21.4 \mathrm{ksi})$

Allowable tensile strain $=0.02$

Allowable compressive strain $=0.05$

Allowable shear strain $=0.04$

Allowable torsional strain $=0.04$

Void conductivity $=16.8 \mathrm{~J}-\mathrm{m} / \mathrm{hr} / \mathrm{m}^{2} /{ }^{\circ} \mathrm{C}\left(0.225 \mathrm{BTU}-\mathrm{in} / \mathrm{hr} / \mathrm{in}^{2} /{ }^{\circ} \mathrm{F}\right)$

Glass transition temperature $=216^{\circ} \mathrm{C}\left(420^{\circ} \mathrm{F}\right)$

The HMHS matrix properties are representative of the 3501-6 resin. The skin laminate consists of forty-eight $0.132 \mathrm{~mm}(0.00521$ in) plies resulting in a composite thickness of $6.35 \mathrm{~mm}(0.25 \mathrm{in})$. The fiber volume ratio is 0.60 . The laminate configuration in $\left[[0 / \pm 45 / 90]_{s}\right]_{6}$. The $0^{\circ}$ plies are in the axial direction of the stiffener, along the $x$ axis indicated in Figure 2a. The width of the stiffened panel is $991 \mathrm{~mm}$ ( $39 \mathrm{in}$ ) and it has a length of $559 \mathrm{~mm}$ (22 in). The stiffener hat sections are made from the same AS-4/HMHS composite structure as the outer skin. The stiffeners are perfectly bonded to the skin at all surfaces of contact. This example is physically very similar to the stiffened composite panel analyzed in Reference [14]. Similar to Reference [14], large displacements are taken into account. The novelty in the present paper is that composite constituent level progressive damage simulation is integrated into the structural analysis of the stiffened panel.

Axially compressive loading is applied by imposing a gradually increasing uniform axial displacement at the clamped edge of the panel. A displacement controlled CODSTRAN simulation is employed to monitor damage initiation and progression as the panel is loaded. Figure 3 shows the relationship between induced loading due to the imposed displacement of the clamped edge and the produced damage during damage initiation and growth stages. First ply failure is in the surface ply of the skin near the end of the stiffener.

The scalar damage variable, shown on the ordinate of the graph in Figure 3, is derived from the total volume of the composite material affected by the various damage mechanisms [5,7]. Computation of the shown scalar damage variable has no interactive feedback on the detailed simulation of composite degradation. CODSTRAN is able to simulate varied and complex composite damage mechanisms via evaluation of the individual ply failure modes and associated degradation of laminate properties. In general, the type of damage growth and the sequence of damage progression depend on the composite structure, loading, material properties, residual stresses induced by the curing process, and hygrothermal conditions.

With reference to Figure 3, damage initiation is under a $635 \mathrm{kN}$ (143 kip) loading by compressive failures in the $0^{\circ}$ first ply at approximately $6.4 \mathrm{~mm}$ from the 


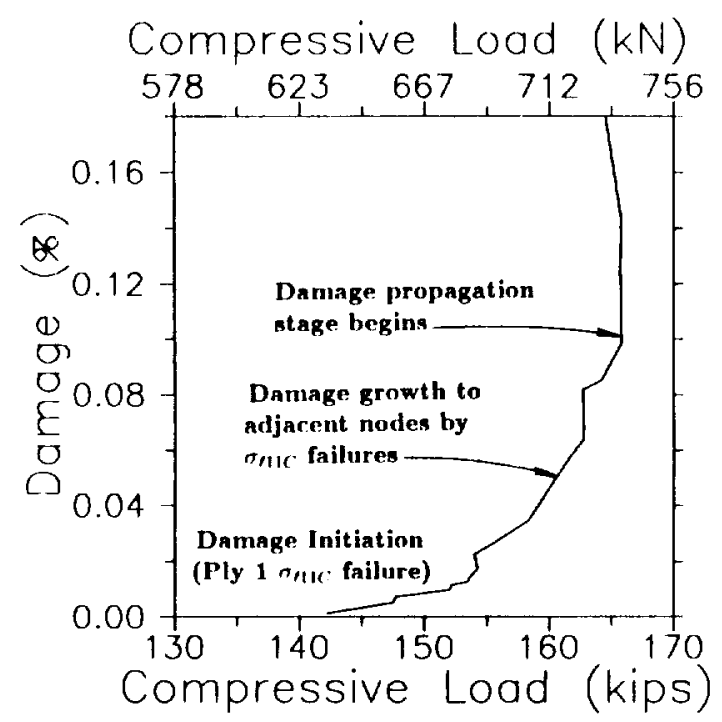

Figure 3. Damage initiation and growth under compressive load AS-4/HMHS $\left.[10 / \pm 45 / 90]_{s}\right]_{6}$.

stiffener web ends toward the clamped edge of the panel. As loading increases, damage grows contiguously in the plane of the skin. Across the laminate thickness, damage growth is first into the zero degree plies. When loading reaches 737 $\mathrm{kN}$, the $\pm 45^{\circ}$ angle plies also begin to participate in damage progression. After the $737 \mathrm{kN}$ loading level, damage growth is accompanied with negligible increase in loading. After a $737.4 \mathrm{kN}$ ultimate load, corresponding to a cumulative damage level of approximately 0.14 percent, the induced compressive load decreases as a through-the-thickness damage propagation stage is entered with increasing global strain. The damage propagation mode is highly localized to the unstiffened composite skin areas immediately adjacent to the ends of the stiffener toe elements.

Figures $4 \mathrm{a}$ and $4 \mathrm{~b}$ show the Ply 1 longitudinal stress contours under a $689 \mathrm{kN}$ load during damage growth. Composite properties are degraded according to the accumulated damage, resulting in the lowering of ply stresses in the damaged regions. Damage is localized to the skin, adjacent to the ends of the stringer toe elements bonded to the skin. Due to the localized nature of damage, the overall pattern of stress contours shown in Figure $4 a$ is not significantly affected during the initial stages of damage. The significant local effects at the damaged region are indicated in Figure $\mathbf{4 b}$ by the detailed stress relief contours.

Figure 5 shows the overall relationship between the applied global strain and the corresponding total axial compressive force in the panel. The CODSTRAN simulation indicated in Figure 5, takes into account geometric nonlinearities caused by large displacements as well as the effects of structural degradation with damage. Linear analysis and geometrically nonlinear analysis results, not taking 


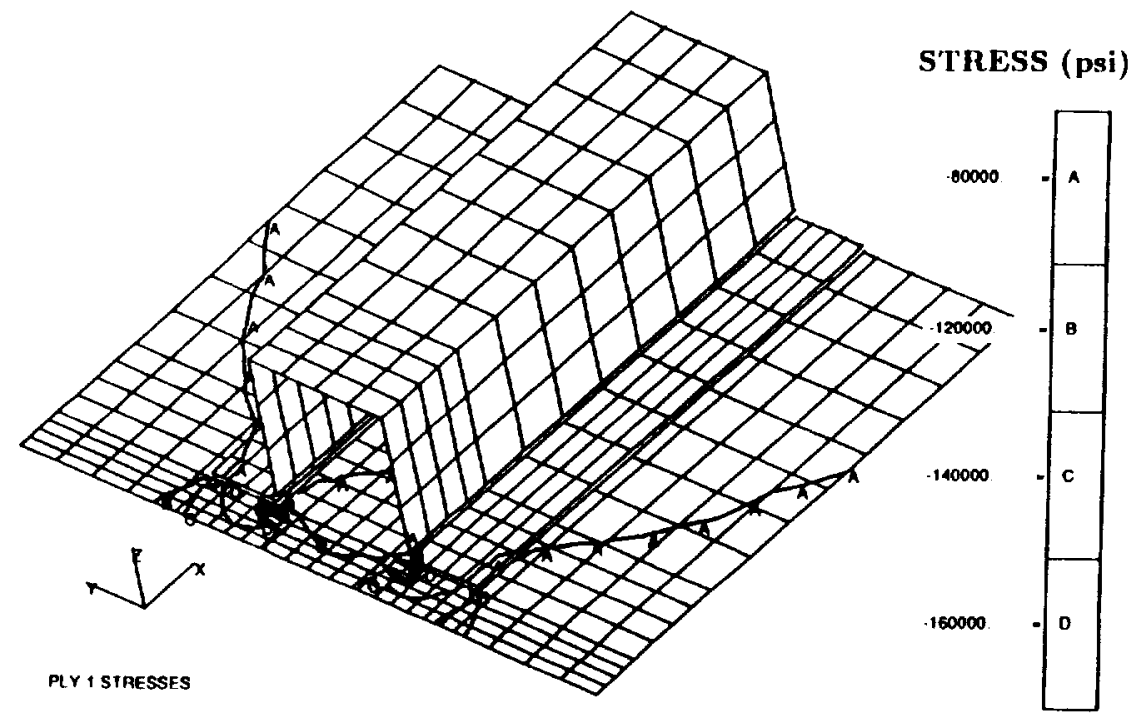

Figure 4a. Ply 1 global longitudinal stress contours after initial damage growth AS-4/HMHS $\left[[0 / \pm 45 / 90]_{s}\right]_{6}$.

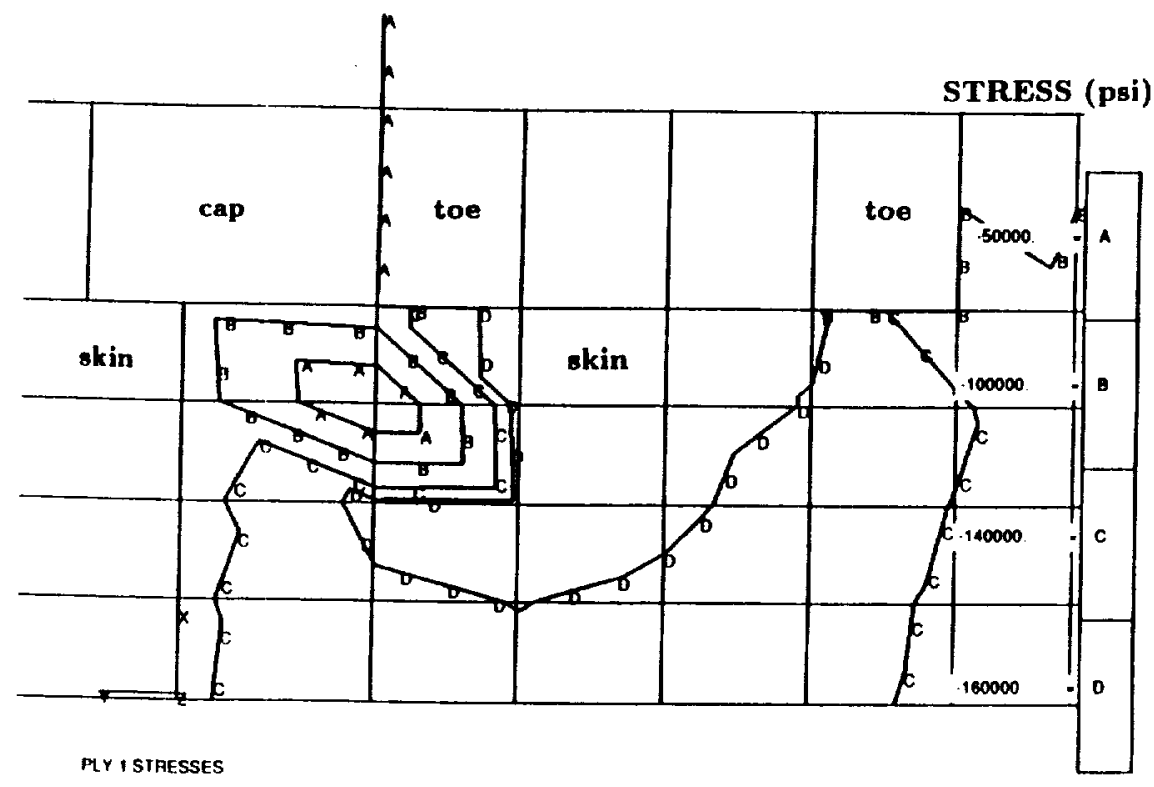

Figure 4b. Ply 1 stress relief details in critical region after initial damage growth AS-4/HMHS $\left[(0 / \pm 45 / 90]_{s}\right]_{6}$. 




Figure 5. Induced compressive load with end displacement AS-4/HMHS $\left[[0 / \pm 45 / 90]_{s}\right]_{6}$.

into account the effects of structural damage, are also shown in Figure 5 for comparison with CODSTRAN simulation. Before the damage initiation stage, CODSTRAN simulation is identical to geometrically nonlinear structural analysis. However, the information provided by CODSTRAN with regard to damage progression and damage tolerance during the various degradation stages cannot be obtained from any traditional linear or nonlinear structural analysis result.

Figure 6 shows the direct relationship between the applied global strain and the volume of damage produced in the composite structure. After the damage initiation stage, overall damage volume increases precipitously yet steadily with the applied global strain through the maximum loading stage and beyond.

A measure of composite structural damage tolerance is obtained by defining the Strain Energy Release Rate (SERR) as the amount of incremental work done on the structure per unit volume of the created damage during degradation [5,7]. Figure 7 shows the SERR as a function of the applied global strain on the panel. The peak SERR level occurs at damage initiation, corresponding to a global deformation of approximately $\mathbf{4 0 0 0}$ microstrains. SERR falls to a much lower level after damage initiation, indicating the lack of damage tolerance of this structure after initial damage. Fluctuations in the SERR indicate changes in the structural resistance against damage under progressive end displacement. The maximum loading level of $737.4 \mathrm{kN}$ (166 kips), corresponding to an applied global deformation of approximately $5100 \mu \epsilon$, is marked by a small but sharp local peak in the SERR.

Figure 8 shows the $z$ components of displacements under a $4500 \mu \epsilon$ global strain during damage growth. The overall displacement contours depicted in Figure 8 


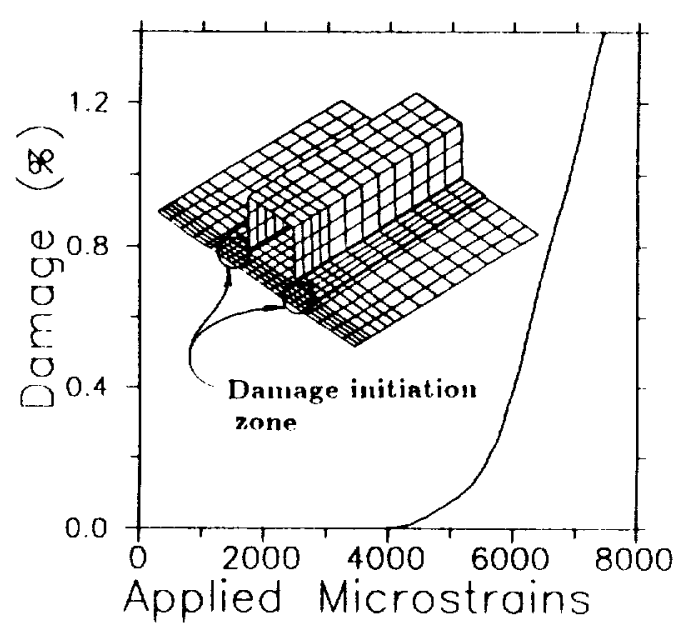

Figure 6. Damage propagation with end displacement AS-4/HMHS $\left[[0 / \pm 45 / 90]_{s}\right]_{6}$.

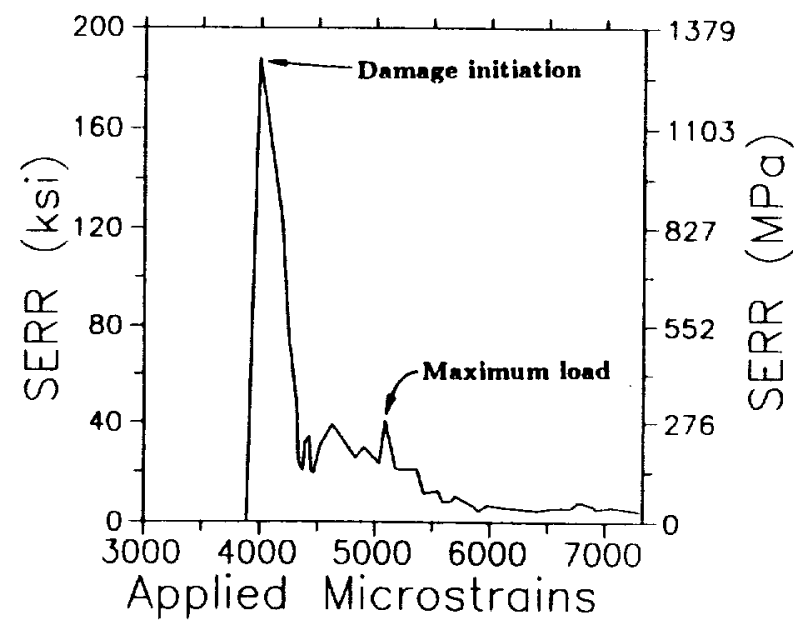






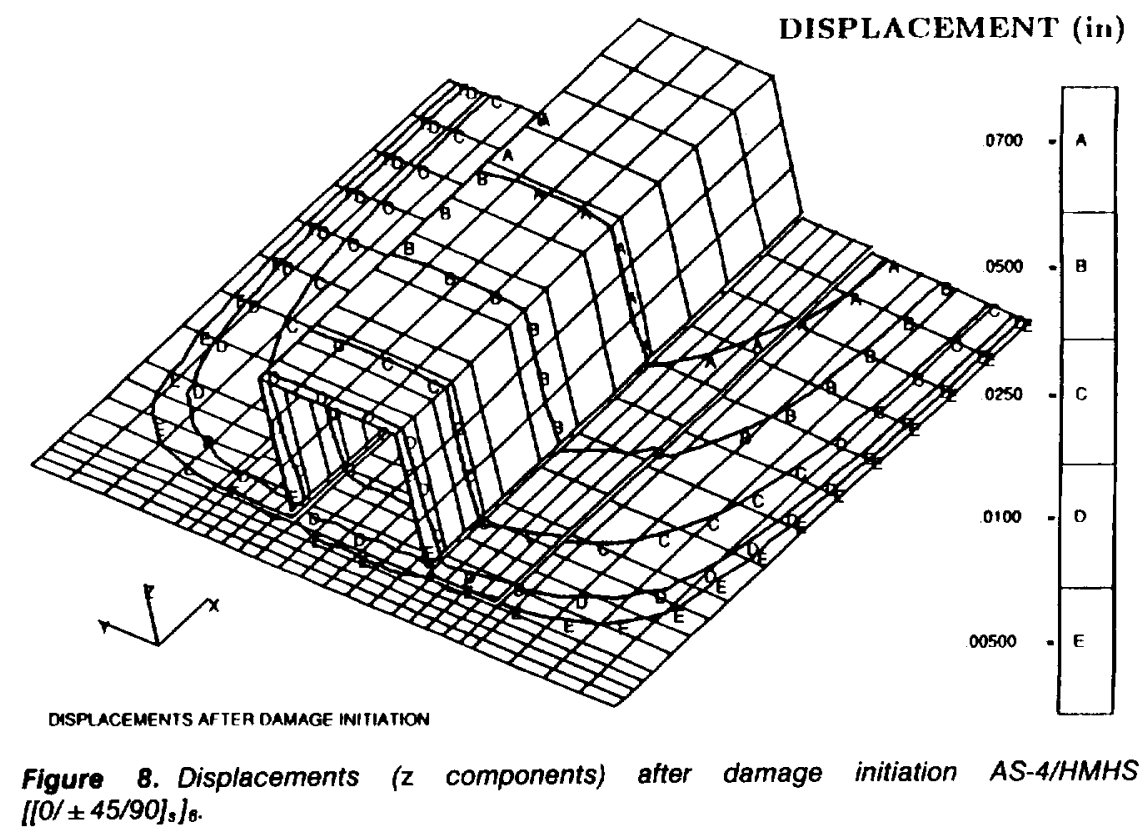

are not affected by the localized damage. Figure 8 indicates that the apparent global response of the stiffened panel, as may be observed during a physical test, does not show any significant signs of the damage progression that is taking place in the plies of the laminate.

Figure 9 shows the $x$ components of displacements under the same $4500 \mu \mathrm{\epsilon}$ global strain as in Figure 8. Axial displacement coutours shown in Figure 9 are only slightly affected near the local damage. Figure 9 indicates that in order to detect damage growth in a laboratory test it is necessary to measure accurately the local strains in the damaged zone.

Figure 10 shows Ply 1 longitudinal stress contours immediately after throughthe-thickness laminate fractures occur under a $737.4 \mathrm{kN}$ (166 kip) ultimate loading. The stress relief contours near the stringer toe edges shown in Figure 10 are indicative of laminate failure locations.

\section{CONCLUDING REMARKS}

The significant results and overtones from this investigation in which CODSTRAN (COmposite Durability STRuctural ANalysis) is used to evaluate structural response of a stiffened composite panel, considering damage initiation and progression effects, are as follows:

1. Computational simulation, with the use of established composite mechanics and finite element modules, can be used to predict the damage tolerance. 


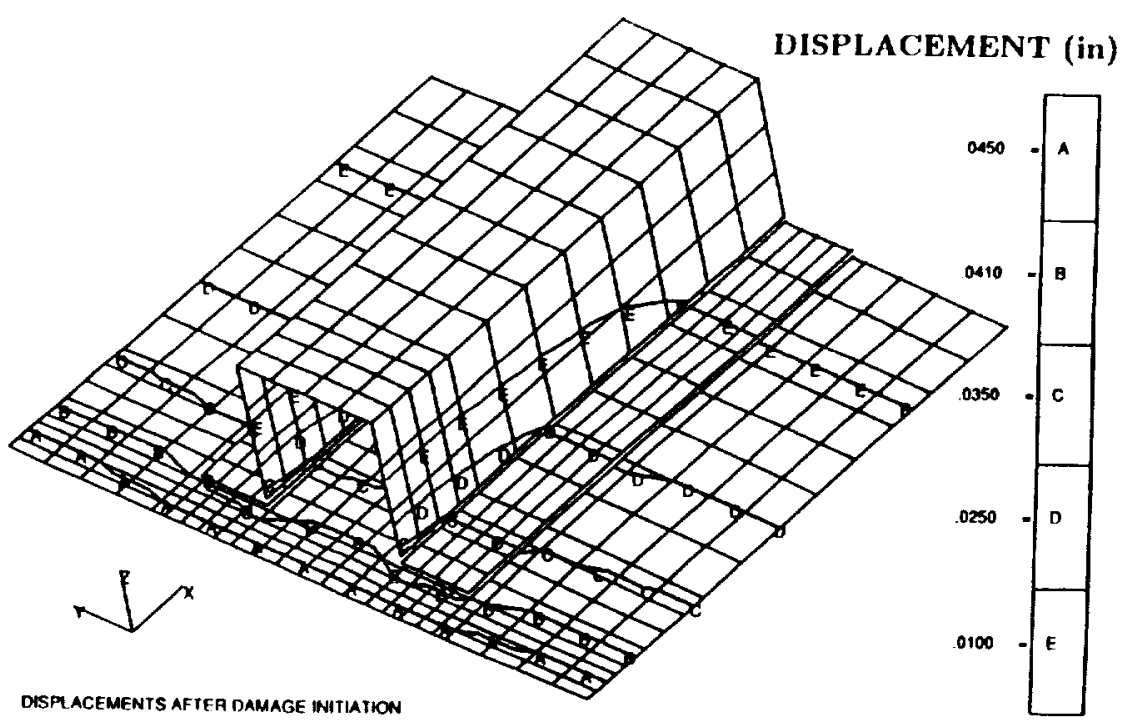

Flgure 9. Axial displacements after damage initiation AS-4/HMHS $\left[[0 / \pm 45 / 90]_{s}\right]_{6}$.

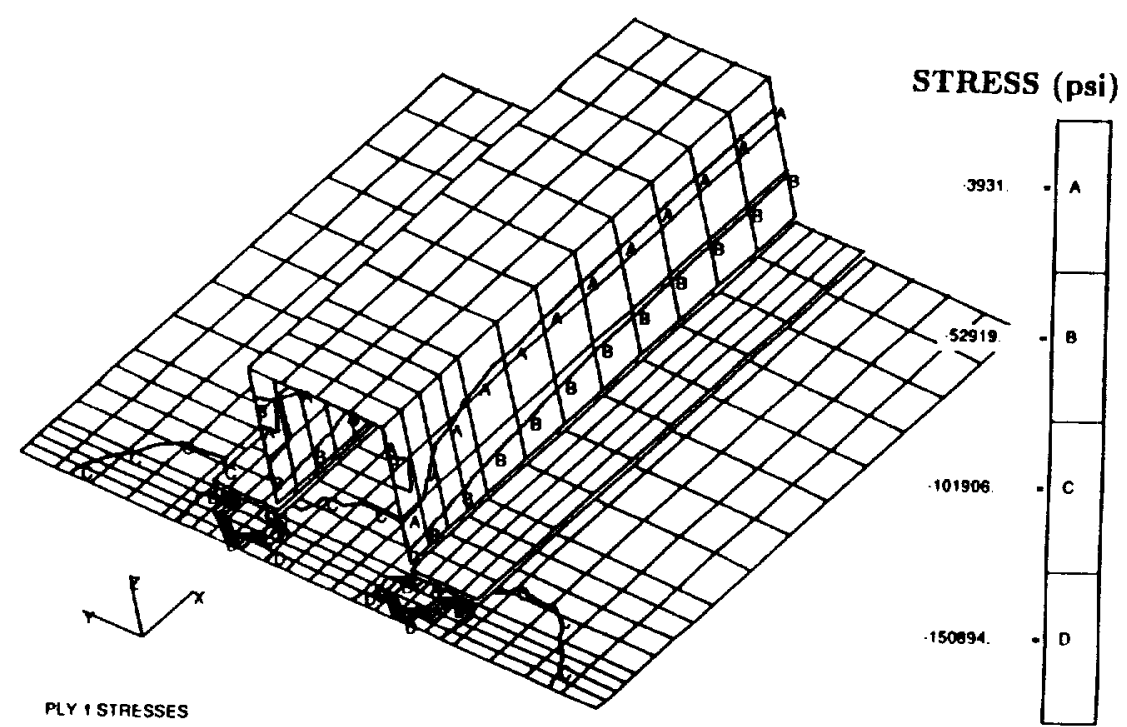

Figure 10. Ply 1 longitudinal stresses after through-the-thickness damage propagation AS4/HMHS $\left[/[0 / \pm 45 / 90]_{s}\right]_{0}$ 
safety, and durability of built-up composite structures such as composite skin panels with integrated stiffeners.

2. CODSTRAN adequately tracks the damage initiation, growth, and subsequent propagation to fracture for any composite structure.

3. Non-destructive evaluation of in-service structural integrity is facilitated by the prediction of damage initiation/progression locations and mechanisms.

4. CODSTRAN simulations may be carried out under either load controlled or displacement controlled conditions.

5. The demonstrated procedure is flexible and applicable to all types of constituent materials, structural geometry, and loading. Hybrid composite structures, composite laminates containing homogeneous materials such as metallic foils, as well as binary composites can be simulated. The hygrothermal environment, residual stresses induced by the curing process, local defects due to fabrication error and/or accidental damage may be included in a CODSTRAN simulation.

6. Fracture toughness parameters such as the structural fracture load and the ultimate load are identifiable for any structure by the demonstrated method. It is also useful to carry out CODSTRAN simulations prior to physical testing to guide the data acquisition strategy and to enable the detailed interpretation of experimental results with regard to damage initiation/progression mechanisms and damage tolerance.

7. The availability of CODSTRAN facilitates composite structural design and certification by allowing the efficient and effective evaluation of design options and by providing early design loads.

8. Computational simulation by CODSTRAN represents a new global approach to structural integrity assessment.

\section{ACKNOWLEDGEMENT}

The participation of the first two authors in this research was sponsored by NASA-Lewis Research Center under grant NAG-3-1101.

\section{REFERENCES}

1. Chamis C. C. and G. T. Smith. 1978. “Composite Durability Structural Analysis," NASA TM79070.

2. Irvine, T. B. and C. A. Ginty. 1986. "Progressive Fracture of Fiber Composites," Journal of Composite Materials, 20(March):166-184.

3. Minnetyan, L., C. C. Chamis and P. L. N. Murthy. 1992. "Structural Behavior of Composites with Progressive Fracture," Joumal of Reinforced Plastics and Composites, 11(4):413-442.

4. Minnetyan, L., P. L. N. Murthy and C. C. Chamis. 1990. "Progression of Damage and Fracture in Composites under Dynamic Loading," NASA TM-1031/8, (April), pp. 16.

5. Minnetyan, L., P. L. N. Murthy and C. C. Chamis. 1990. "Composite Structure Global Fracture Toughness via Computational Simulation," Computers \& Structures, 37(2):175-180.

6. Minnetyan, L., P. L. N. Murthy and C. C. Chamis. 1992. "Progressive Fracture in Composites Subjected to Hygrothermal Environment," International Jourmal of Damage Mechanics, 1(1):60-79. 
7. Minnetyan, L., C. C. Chamis and P. L. N. Murthy. 1991. "Damage and Fracture in Composite Thin Shells," NASA TM-105289. (November).

8. Minnetyan, L., C. C. Chamis and P. L. N. Murthy. 1992. "Structural Durability of a Composite Pressure Vessel." Journal of Reinforced Plastics and Composites, 11(4):1251-1269.

9. Chamis, C. C., P. L. N. Murthy and L. Minnetyan. 1992. "Progressive Fracture of Polymer Matrix Composite Structures: A New Approach," NASA TM-105574, (January), p. 22.

10. Minnetyan, L., J. M. Rivers, P. L. N. Murthy and C. C. Chamis. 1992, "Structural Durability of Stiffened Composite Shells," Proceedings of the 33rd SDM Conference, Dallas, TX: 5(April):2879-2886.

11. Minnetyan, L. and P. L. N. Murthy. 1992. "Design for Progressive Fracture in Composite Shell Structures," Proceedings of the 24th International SAMPE Technical Conference. Toronto, Canada, October 20-22, pp. T227-T240.

12. Murthy, P. L. N. and C. C. Chamis. 1986. Integrated Composite Analyzer (ICAN): Users and Programmers Manual, NASA Technical Paper 2515, (March)

13. Nakazawa, S., J. B. Dias and M. S. Spiegel. 1987. MHOST Users' Manual, Prepared for NASA Lewis Research Center by MARC Analysis Research Corp., (April)

14. Wang, J. T., C. G. Lotts, D. D. Davis, Jr. and T. Krishnamurthy, 1992. "Coupled 2D-3D Finite Element Method for Analysis of a Skin Panel with a Discontinuous Stiffener," Proceedings of the 33rd SDM Conference, Dallas, TX: 2(April):818-827. 